\title{
PHYTOCHEMICAL ANALYSIS AND IN VITRO BIOLOGICAL CHARACTERIZATION OF AQUEOUS AND METHANOLIC EXTRACT OF BACOPA MONNIERI
}

\author{
ROMANA PARVEEN ${ }^{1}$, TOOBA NAZ SHAMSI' ${ }^{1}$, HIMANSHU KUMAR², SADAF FATIMA1* \\ 1Department of Biotechnology, Jamia Millia Islamia, New Delhi 110025, India, ${ }^{2}$ Amity Institute of Biotechnology, Amity University, Noida, \\ Uttar Pradesh 201303, India
}

Email: sfatima1@jmi.ac.in

Received: 17 Aug 2016 Revised and Accepted: 05 Oct 2016

\begin{abstract}
Objective: The present study was designed to identify the phytocompounds, to compare the antibacterial, antioxidant, and anti-inflammatory effects of aqueous and methanolic extract of Bacopa monnieri.

Methods: Antioxidant activity was determined by 1, 1-diphenyl-2-picrylhydrazyl (DPPH), Ferric Reducing Antioxidant Power (FRAP), Super oxide dismutase (SOD), Reduced glutathione (GSH), Catalase assays. Anti-inflammatory activity was measured with inhibition of albumin denaturation and trypsin inhibitory assay. Finally, extracts were tested against various pathogenic bacterial and fungal strains by broth dilution assay and disc diffusion assay respectively.

Results: Results showed the presence of alkaloids, flavonoids, phenols, quinines and glycosides etc while steroids and carboxylic acid were absent. The extracts demonstrated free radical-scavenging activity quite comparable with standard ascorbic acid. Methanolic extract exerted comparative higher antioxidant and anti-inflammatory activity than aqueous extract. Both extracts were most effective against Bacillus subtilis and lowest inhibition against Staphylococcus aureus.

Conclusion: The results obtained clearly indicated a promising potential of B. monnieri for serving as a strong ROS scavenger, might be used as antiarthritic and strong natural antibiotic agent for effective treatment of various oxidative stressed disorders (cancer, cardiovascular diseases),
\end{abstract} inflammatory disorders (rheumatoid arthritis) and various bacterial infections.

Keywords: Phytochemicals, Antioxidants, Anti-inflammatory, B. monnieri, Ayurveda, Antibacterial

(c) 2016 The Authors. Published by Innovare Academic Sciences Pvt Ltd. This is an open access article under the CC BY license (http://creativecommons.org/licenses/by/4. 0/) DOI: http://dx.doi.org/10.22159/ijpps.2016v8i12.14739

\section{INTRODUCTION}

For the treatment of human diseases, the natural products like plants, animals, minerals are being used. Right from the existence of human civilization, the medical science had been performed practically. The fate of natural ingredients in drug discovery will be more holistic, personalized and involve proper benefit of primal and current therapeutic skills in a complementary manner so that maximum benefits can be accrued to the patients and the community [1]. Ayurveda is still one of the most primitive and most practised worldwide and has a good philosophical and practical basis [2, 3]. Recently some work in drug development relates to species of Picrorhiza (hepatoprotective), Commiphora (used as a hypolipidemic agent), Bacopa (memory booster), Asclepias (cardiotonic) and Curcuma (anti-inflammation) [4, 5].

B. monnieri (Linn), commonly named as "Brahmi," belongs to the family Scrophulariaceae is an Indian valuable herb [6]. It has been used in Ayurvedic system of medicine traditionally to treat conditions such as fever, inflammation, asthma, epilepsy, pain and memory retardation [7]. As far as the therapeutic importance of B. monnieri in indigenous systems of medicine was found, chemical examinations of the wide variety of plants have also been carried out by many researchers. Some basic investigations reported the separation of the 'brahmine' (alkaloid) from B. monnieri followed by identification of some other alkaloids including nicotine and herpestine [8], Dmannitol, saponin, hersaponin and potassium salts [9]. The memory enhancing activity of the $B$. monnieri has been attributed due to the presence of two major saponins bacoside A and B [10,11]. Some major phytocompounds reported in this plant include; phenylethanoid glycosides, amino acids such as $\alpha$-alanine, betulinic acid aspartic acid, glutamic acid, and betulinic acid, stigmasterol, $\beta$-sitosterol, flavonoids and stigmastanol [12]. Steroidal saponins and Bacosides A and B are the active chemical constituents that are responsible for enhancing both learning and memory $[8,13-15]$. Some of the chemical elements of B. monnieri are lipophilic. This means that they can integrate with or dissolve in lipids providing them the ability to pass the blood-brain barrier $[16,17]$.

Antioxidants had the property to prevent oxidative damage by free radicals that are amenable for variety of human diseases like hypertension, arthrosclerosis, gastritis, Diabetes mellitus, arthritis, ischemia, AIDS and Alzheimer's disease [18]. Bacosides are known to feed on various free radicals such as peroxides, superoxides and hydroxyl radicals $[19,20]$. Previously, antioxidant activity of alcoholic and the hexane extract of $B$. monnieri on lipid peroxidation by cumene hydro peroxide and ferrous sulphate in the homogenate of rat liver is documented [21]

It is documented that different mechanisms involved in the neuroprotective and memory boosting effects of $B$. monnieri, such as the attraction and detoxification of metal ions [22, 23], free radical scavenging [24], or improving antioxidant activity have gained much attraction [25]. Animal models have depicted that B. monnieri can employ vasorelaxant, adaptogenic, anti-inflammatory, chelation of metal ions, and cholinergic modulatory effects [26-30]. B. monnieri also shows to inhibit numerous $\beta$-amyloid oxidative stress pathways responsible in $\mathrm{AD}$ pathology and antioxidant properties related to GSH redox state [31]. Modern studies on B. monnieri adumbrate that its treatment may cause reversible inhibition of spermatogenesis and fertility [32].

As stress is a cause in many diseases, research on a productive antistress agent isolated from plants has gained much concern. Researchers have estimated the effect of $B$. monnieri extract against acute stress and consistent stress models in rats. Various studies on B. monnieri proved its antioxidant effects with metal ion reduction, free scavenging and super oxide dismutase activities and they might be the root of treatment for oxidative stressed diseases including asthma, epilepsy, insanity, inflammation and Cyclic vomiting syndrome diseases [33]. Propanoic and ethanolic extracts of $B$. 
monnieri showed antimicrobial activity conversely against various bacterial etiological agents such as Escherichia coli, Streptococcus, Staphylococus aureus, Bacillus subtilis, Klebsiella pneumoniae, Pseudomonas aeroginosa [34-36]. The phytochemicals such as betulinic acid, wogonin and oroxindin isolated from the aerial parts of $B$. monnieri showed aphoristic antifungal activity against Alternaria alternata and Fusarium fusiformis [37].

The Indian herb B. monnieri may be used as a dietary antioxidant, with certain modes of action to prevent the brain system against oxidative damage and age-related cognitive reduction [38-40]. Current study aimed to identify the phytochemical ingredients of $B$. monnieri extracts followed by the evaluation of in vitro antioxidant, anti-inflammatory, antibacterial and antifungal properties of the aqueous and methanolic extract of $B$. monnieri.

\section{MATERIALS AND METHODOS}

\section{Plant material}

The whole plant of $B$. monnieri was obtained from the local Ayurvedic clinic, Rampur, Uttar Pradesh. The plant material was identified by the Faculty of Science, Jamia Hamdard, New Delhi (JH/HG/21/2016).

\section{Chemicals and reagents}

All solvents and chemicals (analytical grade) used for antioxidant, anti-inflammatory, antibacterial and antifungal assay were purchased from Merck and Himedia. DPPH, TPTZ (2,4,6-Tri(2pyridyl)-s-triazine) were purchased from Sigma-Aldrich.

\section{Microorganisms}

The bacterial strains investigated are identified strains and were obtained from NCCS, Pune, India. The studied bacterial strains include Staphylococcus aureus (MTCC 902), E. coli (MTCC 443), Bacillus subtilis (MTCC 736), Pseudomonas aeruginosa (MTCC 2453). All the test bacterial stock cultures were maintained at $4{ }^{\circ} \mathrm{C}$ on nutrient agar slants.

\section{Preparations and extraction procedures of $B$. monnieri aqueous and methanolic extract}

The aqueous and methanolic extract of $B$. monnieri was prepared by dissolving $1 \mathrm{~g}$ of $B$. monnieri in $20 \mathrm{ml}$ of solvents i.e. distilled water (DW) and methanol respectively. The sample was soaked for 24-48 h for the complete extraction of all important phytochemical constituents. Further, it was strained through muslin cloth. The samples were then centrifuged and the supernatants were collected. The supernatant served as B. monnieri aqueous extract (BmAE) and B. monnieri methanolic extract (BmME) for the further evaluation.

\section{Identification of phytocompounds from BmAE and BmME}

The extracts BmAE and BmME were qualitatively tested to identify the presence of phytochemicals such as alkaloids, phenols, amino acids, flavonoids, saponins, tannins, quinones, carbohydrates, glycosides, steroids, carboxylic acids, resins, proteins and terpenoids according to the method described by [58].

\section{Evaluation of antioxidant potential of BmAE and BmME \\ DPPH assay}

BmAE, BmME and the standard ascorbic acid were checked for their antioxidant potential on the basis of free radical scavenging effect of stable DPPH according to the protocol of Goveas and Abraham. With minor modifications [41]. A range of diluted working solutions of the BmAE and BmME were prepared in distilled water and methanol respectively. The aqueous solution of ascorbic acid $(1 \mathrm{mg} / \mathrm{ml})$ was also prepared for the comparative analysis. DPPH $(0.1 \mathrm{mmol})$ was prepared in $80 \%$ methanol and $500 \mu \mathrm{l}$ of this solution was mixed with $500 \mu \mathrm{l}$ of serially diluted sample and standard ascorbic acid solutions separately. The obtained reaction mixtures were kept in dark for 15-30 min and absorbance was recorded at $517 \mathrm{~nm}$ spectrophotometrically. DPPH solution was used as control and the range of diluted BmAE and BmME was taken as blank. The absorbance was recorded and DPPH scavenging was calculated using the formula given below:
DPPH scavenging Activity (\%) = [(Ac-At)/Ac $] \times 100$,

Where Ac and At represent absorbance of control and test sample respectively.

\section{Superoxide dismutase (SOD) assay}

SOD assay was performed according to the method of Kakkar et al. with minor modification [42]. The assay mixture contained $0.2 \mathrm{ml}$ of $\mathrm{BmAE}$ and BmME in water and methanol, $1.2 \mathrm{ml}$ of sodium pyrophosphate buffer, $0.1 \mathrm{ml}$ of Phenazine methosulfate (PMS), and $0.3 \mathrm{ml}$ of Nitro blue tetrazolium chloride (NBT) in a total volume of $1.8 \mathrm{ml}$. The reaction was initiated by the addition of $0.2 \mathrm{ml}$ of Nicotinamide Adenine Dinucleotide (NADH). The assay mixture was incubated at $30^{\circ} \mathrm{C}$ for 5-10 min and glacial acetic acid was added for termination of the reaction. $4.0 \mathrm{ml} \mathrm{n}$-butanol was also added to the reaction mixture and allowed to stand for $10-20 \mathrm{~min}$ at room temperature and then centrifuged. The intensity of the chromogen developed in layer of butanol was recorded at $560 \mathrm{~nm}$. One unit of enzyme activity is defined as the amount of extract that gave $50 \%$ inhibition of NBT reduction in one minute. SOD assay is based on inhibition of formation of NADH-PMS-nitroblue tetrazolium formazon. The colour formed at the end of reaction can be extracted into butanol and measured at $560 \mathrm{~nm}$.

\section{Catalase assay}

Catalase activity was assayed following the method of Jambunathan et al. with minor modification [43]. $\mathrm{H}_{2} \mathrm{O}_{2}$-Phosphate buffer $(3.0 \mathrm{ml})$ was taken in an experimental cuvette, followed by the rapid addition of $40 \mu$ of $\mathrm{BmAE}$ and BmME and mixed thoroughly. The time required for a drop in absorbance by 0.05 units was noted at $240 \mathrm{~nm}$. The $\mathrm{H}_{2} \mathrm{O}_{2}$-Phosphate buffer was served as control. One enzyme unit was calculated as the amount of enzyme present in extracts required to decrease the absorbance at $240 \mathrm{~nm}$ by 0.05 units. The UV absorption of $\mathrm{H}_{2} \mathrm{O}_{2}$ can be measured at $240 \mathrm{~nm}$, whose absorbance decreases when degraded by the enzyme catalase. From the decrease in absorbance, the activity of enzyme found in extracts can be calculated.

\section{Reduced glutathione (GSH) assay}

Reduced glutathione (GSH) was determined by the method of Moron et al. with minor modification [44]. $0.2 \mathrm{ml}$ of BmAE and BmME of different concentration was taken and volume was maintained up to $1.0 \mathrm{ml}$ with $0.2 \mathrm{M}$ sodium phosphate buffer (pH 8.0). Standard GSH was also prepared to concentrations ranging from 2-10 n moles. $2.0 \mathrm{ml}$ of freshly prepared 5,5'-Dithiobis 2-nitrobenzoic acid (DTNB) solution was added to the reaction mixture. After $10 \mathrm{~min}$, the intensity of the developed yellow colour was measured in a spectrophotometer at $412 \mathrm{~nm}$. The results were expressed in $\mu \mathrm{M} / \mathrm{min} / \mu \mathrm{l}$ of both the extracts.

\section{Ferric reducing antioxidant power (FRAP) assay}

The antioxidant potential of BmAE and BmME was assessed based on the Ferric Reducing Antioxidant Power (FRAP) assay by the method of Sudha et al. with minor modification [45]. A total of $75 \mu \mathrm{l}$ of BmAE and BmME and $225 \mu \mathrm{l}$ of DW and methanol respectively were added to 1.5 $\mathrm{ml}$ of freshly prepared FRAP reagent [10 parts of $300 \mathrm{mmol}$ sodium acetate buffer of $\mathrm{pH} 3.6,1$ part of $10 \mathrm{mmol}$ 2,4,6-tri (2-pyridyl)-s-triazine (TPTZ) solution and 1 part of $20 \mathrm{mmol} \mathrm{FeCl}_{3} .6 \mathrm{H}_{2} \mathrm{O}$ ]. The reaction mixture was incubated in the dark for $4 \mathrm{~min}$. The increase in absorbance with the formation of colored product (ferrous tripyridyltriazine complex) was recorded at $593 \mathrm{~nm}$. FRAP working solution was taken as blank. The antioxidant capacity of the BmAE and BmME was determined based on a calibration curve plotted using $\mathrm{FeSO}_{4} .7 \mathrm{H}_{2} \mathrm{O}$ at a concentration ranging between 0.125 and $2 \mathrm{mmol}$ taking the concentration of $\mathrm{FeSO}_{4} .7 \mathrm{H}_{2} \mathrm{O} \mathrm{mmol}$ on x-axis and the absorbance at 593 $\mathrm{nm}$ on y-axis. Results were expressed in mmol Fe (II)/g of extract. The relative activity of the extracts was compared to standard ascorbic acid and analysed in parallel. Absorbance of each diluted extract and standard were expressed in mmol of FRAP value.

\section{Evaluation of anti-inflammatory activity}

\section{Inhibition of albumin denaturation}

The anti-inflammatory assay was done according to the method of Mizushima et al. with minor changes [46]. A range of diluted 
working solutions of the BmAE and BmME were prepared and mixed with $1 \%$ aqueous solution of bovine serum albumin (BSA) fraction. The reaction mixtures were incubated at $37{ }^{\circ} \mathrm{C}$ for $20 \mathrm{~min}$ and then heated at $57^{\circ} \mathrm{C}$ for $20 \mathrm{~min} .1 \% \mathrm{BSA}$ was taken as control and water was taken as blank. Aspirin $(100 \mu \mathrm{g} / \mathrm{ml})$ was taken as standard drug. After cooling the samples, the turbidity was measured spectrophotometrically at $660 \mathrm{~nm}$. Percent inhibition of protein denaturation was calculated using formula:

Percentage inhibition $=\left(\mathrm{Abs}_{\text {control }}-\mathrm{Abs}_{\text {sample }}\right) \times 100 / \mathrm{Abs}_{\text {control }}$

\section{Proteinase inhibitory action}

The test was performed according to the modified method of Oyedepo et al. [47]. $0.06 \mathrm{mg}$ trypsin was added to the reaction mixture containing $1 \mathrm{ml}$ of $20 \mathrm{mmol}$ Tris- $\mathrm{HCl}$ buffer (pH 7.4) and 1 $\mathrm{ml}$ of diluted sample of BmAE and BmME with water and methanol respectively. The assay mixture was incubated at $37^{\circ} \mathrm{C}$ for $10-15$ min and then $1 \mathrm{ml}$ of $1 \%(\mathrm{w} / \mathrm{v})$ casein was added. The assay mixture was further incubated for an additional $20 \mathrm{~min}$. $70 \%$ perchloric acid was added to the mixture in order to arrest the reaction. Precipitated protein suspension was then centrifuged and the absorbance of the supernatant was read at $210 \mathrm{~nm}$. The inhibition of proteinase inhibitory activity in percentage was calculated.

$$
\begin{gathered}
\text { Percentage proteinase inhibition }=\left(\mathrm{Abs}_{\text {control }}-\mathrm{Abs}_{\text {sample }}\right) \mathrm{X} \\
100 / \mathrm{Abs}_{\text {control. }}
\end{gathered}
$$

\section{Evaluation of antimicrobial activity}

\section{Determination of antibacterial activity}

Antimicrobial activity of the BmAE and BmME was tested against four bacterial strains (Pseudomonas aeruginosa, Bacillus subtilis, Staphylococcus aureus and Escherichia coli) as per the method of Barbade and Datar with few modifications [45]. Overnight cultures were prepared in Luria broth (LB) media by inoculating a single colony from agar plates and incubated at $37{ }^{\circ} \mathrm{C}$ for $12 \mathrm{~h}$. Overnight cultures were diluted with fresh LB media to approximately $10^{4}$ colony forming units (CFU) and incubated at $37^{\circ} \mathrm{C}$ for $12-14 \mathrm{~h}$ in the presence of BmAE and BmME compared to the growth of the control culture where only media and bacterial inoculums was present. Experiment was repeated twice for the confirmation. The absorbance was recorded at $600 \mathrm{~nm}$. The percentage inhibition was calculated by using the formula:

$$
\text { Percentage Inhibition }(\%)=[(d c-d t) / d c] \times 100 \text {, }
$$

Where dc and dt represent the absorbance of control and treated sample strains respectively.

\section{Determination of antifungal activity}

The minimum inhibitory concentration of BmAE and BmME against Candida cells (ATCC 10261 and ATCC 90028) was determined by broth dilution method. Cultures were grown with or without test compounds in the media. Two fold dilutions of the test compound were carried out as an initial step. Also, antifungal activity of BmAE and BmME in solid media was determined by the Disc Diffusion Method. Candida cells $\left(10^{5} \mathrm{cells} / \mathrm{ml}\right)$ were inoculated in molten YEPD agar $\left(\sim 40^{\circ} \mathrm{C}\right)$ and poured into a petriplates. Filter discs were placed on solid agar and different concentrations of test compounds were applied on the disc in $10 \mu \mathrm{l}$ volume. The average diameter of the zone of inhibition was recorded in $\mathrm{mm}$.

\section{Statistical analysis}

The experiments were done in triplicates. Results were expressed as graphs representing mean \pm SEM (Standard Error of Mean) using the software Graph Pad Prism 5.0.

\section{RESULTS}

\section{Identification of phytocompounds from BmAE and BmME}

Qualitative phytochemical analysis of aqueous and methanolic extracts of B. monnieri plant revealed the presence of phenolics and non-phenolics phytocompounds such as total phenols, tannins and flavonoids, alkaloids, sterol, resins, terpenoids, xanthoproteins, quinones, glycosides and saponins while the steroids and carboxylic acids were absent in both type of extracts. Other compounds were found in fairly detectable quantity (table 1).

Table 1: Phytochemical composition of methanolic and aqueous extracts of $B$. monnieri

\begin{tabular}{lll}
\hline Phytochemical constituents & BmAE & BmME \\
\hline Alkaloids & + & + \\
Flavonoids & + & + \\
Steroids & - & - \\
Saponins & + & + \\
Phenols & + & + \\
Resins & + & + \\
Tannins & + & + \\
Terpenoids & + & + \\
Xanthoproteins & + & + \\
Quinones & + & + \\
Glycosides & + & + \\
Carboxylic acid & - & - \\
\hline
\end{tabular}

Evaluation of antioxidant potential of BmAE and BmME

\section{DPPH assay}

The decrease in the absorbance of the DPPH radical caused by antioxidant was due to the scavenging of the radical by hydrogen donation. It is visually noticeable as the colour changes from purple to yellow. B. monnieri showed DPPH radical scavenging activity in a concentration-dependent manner as shown in the fig. 1. The BmAE and BmME showed DPPH radical scavenging activity in a concentrationdependent fashion with the highest and lowest scavenging at amount $500 \mu \mathrm{l}$ and $50 \mu \mathrm{l}$ of the extracts. BmAE demonstrated highest \% DPPH radical scavenging of $94.19316 \pm 0.0047 \%$ and lowest of $17.18339 \pm 0.0059 \%$. While the BmME showed highest \%DPPH radical scavenging of $94.7942 \pm 0.0050 \%$ and minimum of $24.47114 \pm 0.0052 \%$. The results were quite comparable to that of standard i.e. ascorbic acid with maximum \% DPPH scavenging of $99.67775 \pm 0.0053 \%$ and minimum of $61.81149 \pm 0.0046 \%$.

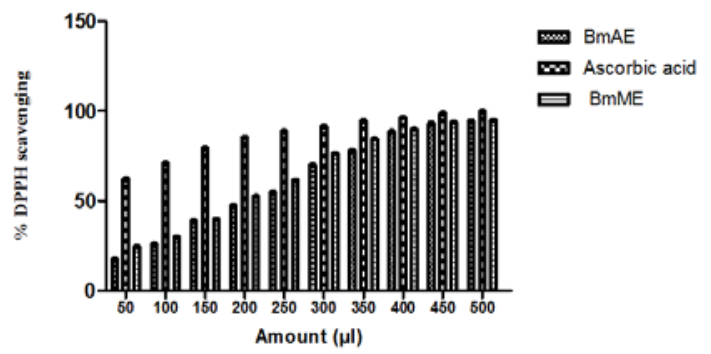

Fig. 1: 1, 1-diphenyl-2-picrylhydrazyl fr ee radical scavenging activity of methanolic and aqueous extract of $B$. monnieri were calculated and compared to ascorbic acid i.e. standard. The activity increased in time and concentration dependent manner. Results represent the means \pm SEM (standard error of mean) from at least three separate experiments

\section{SOD assay}

SOD molecules are known to convert superoxide free radicals to hydrogen peroxide and molecular oxygen. It is a major defense for aerobic cells in combating the toxic effects of superoxide radicals. They belong to a large family of isoenzymes that mediate cellular response to oxidative stress and represent the main enzymatic source of peroxides. The degradation of superoxide radicals per minute was evaluated and this radical was degraded on an average unit of 0.006 by BmAE and 0.023 units by BmME (fig. 2).

\section{Catalase assay}

The UV absorption of hydrogen peroxide can be measured at $240 \mathrm{~nm}$, whose absorbance decreases when degraded by the enzyme catalase. 
From the decrease in absorbance, the enzyme activity can be portrayed as the concentration of hydrogen peroxide is decreasing significantly in dose-dependent manner. The $100 \%$ hydrogen peroxide was degraded to $75.16246 \pm 0.0063 \%$ and $71.58474 \pm 0.0067 \%$ when initially small amount of BmAE and BmME was added to the cuvette respectively. Degradation per minute observed upto $10 \mathrm{~min}$ and finally there was approximately $7.889728 \pm 0.0068 \%$ and $2.229903 \pm 0.0059 \%$ radical was remained (fig. 3 ).

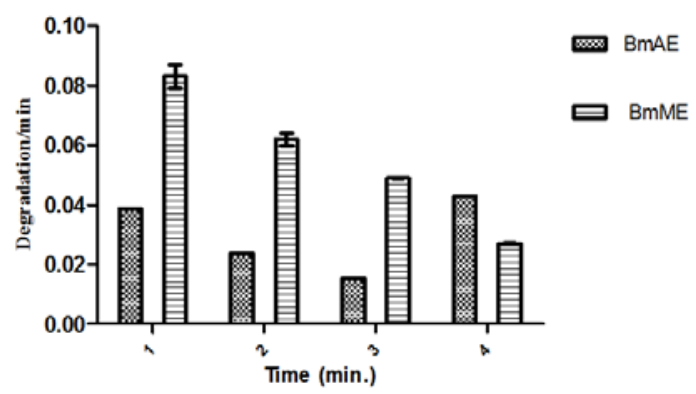

Fig. 2: Superoxide radical level significantly decreased with increase in concentration of methanolic and aqueous extract of $B$. monnieri. The results were expressed in degradation/min. Results represent the mean $\pm S E M$ from at least three separate experiments

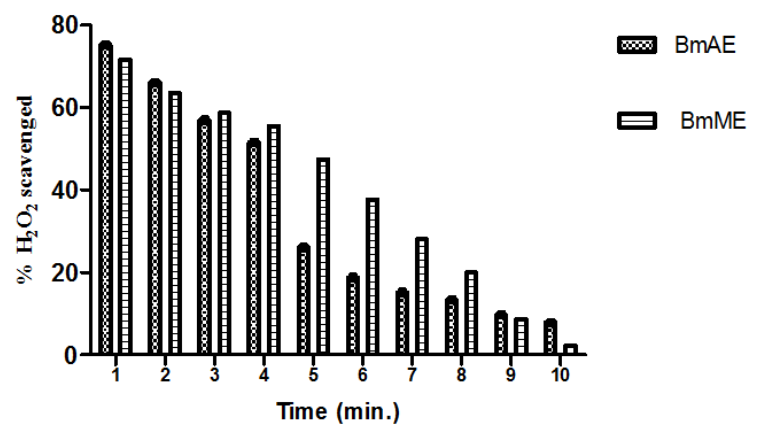

Fig. 3: Hydrogen peroxide scavenging (\%) was assessed with increasing amount of methanolic and aqueous extract of $B$. monnieri. The hydrogen peroxide degradation increased in concentration dependent manner. Results represent the mean \pm SEM from at least three separate experiments

\section{Reduced glutathione assay}

Glutathione peroxidase catalyses the reduction of hydrogen peroxides by reduced glutathione (GSH) and functions to protect the cell from oxidative damage. GSH is the important part of nonenzymatic antioxidants and it can remove peroxy nitrite (ONOO-) with the formation of oxidized glutathione (GS-SG), which is converted back into GSH by NADPH-dependent glutathione reductase. Reduced glutathione on reaction with DTNB $(5,5$ 'dithiobis nitro benzoic acid) produces a yellow coloured product that absorbs at $412 \mathrm{~nm}$. DTNB was used as control and the DTNB with different concentration of BmAE and BmME was used as test sample. The concentration of GSH was expressed in $\mu \mathrm{M} / \mathrm{min} / \mu \mathrm{l}$ extract and estimated upto $200 \mu \mathrm{l}$ of both extracts. GSH was found in low concentration at $50 \mu \mathrm{l}$ and in high concentration at $200 \mu \mathrm{l}$ volume of both BmAE and BmME (fig. 4).

\section{FRAP assay}

This assay measures the ability of antioxidants in the samples to reduce the ferric ions to a coloured ferrous product at $593 \mathrm{~nm}$. The results showed that FRAP value of $B$. monnieri increases in the concentration-dependent manner. The highest absorbance of FRAP was observed in B. monnieri at $500 \mu \mathrm{l}$ and the lowest was that at $50 \mu \mathrm{l}$ in both BmAE and BmME with a maximum FRAP value
$1.0527 \pm 0.065 \mathrm{mmol}$ and $1.0067 \pm 0.041 \mathrm{mmol}$ and minimum value of $0.3027 \pm 0.052 \mathrm{mmol}$ and $0.275 \pm 0.057 \mathrm{mmol}$ respectively as compared to standard maxima at $1.1847 \pm 0.049 \mathrm{mmol}$ and minimal at $0.373 \pm 0.032 \mathrm{mmol}$ respectively. These concentrations were effective to react with ferric tripyridyltriazine (Fe'II-TPTZ) complex and produce a blue coloured ferrous tripyridyltriazine (Fe"I-TPTZ). From the observations, it is clear that B. monnieri showed fair antioxidant activity comparable to ascorbic acid (fig. 5).

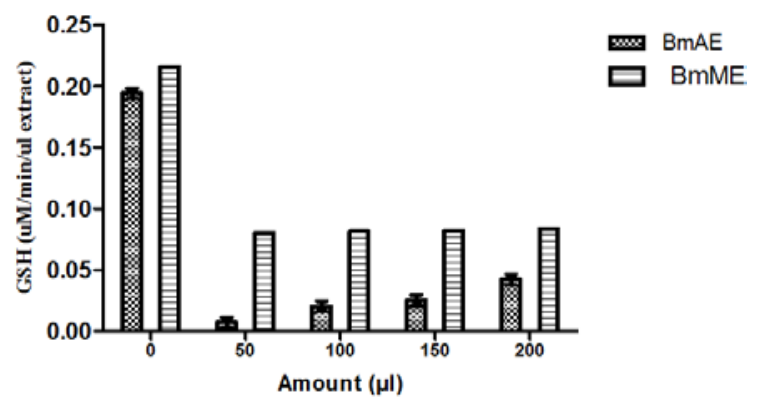

Fig. 4: Reduced glutathione concentration in $\mu \mathrm{M}$ was estimated in presence of methanolic and aqueous extract of B. monnieri. The amount of reduced glutathione increased with increase in amount of extract. Results represent the mean \pm SEM from at least three separate experiments

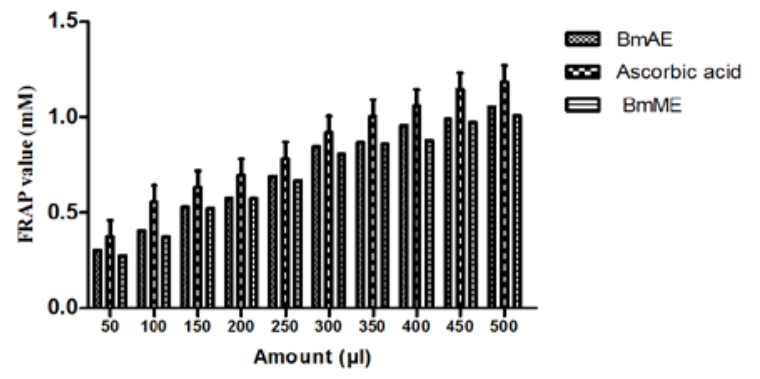

Fig. 5: Ferric Reducing Antioxidant Power of methanolic and aqueous extract of $B$. monnieri was estimated and compared to ascorbic acid as standard. The results were expressed in $\mathbf{~ m o l}$. Results represent the mean \pm SEM from at least three separate experiments

\section{Evaluation of Anti-inflammatory activity}

\section{Inhibition of albumin denaturation}

If there occurs any infection or damage to the body or tissue then body respond against the infection through inflammation. Protein denaturation is one of the major causes of inflammation. Due to this, we have tried to find out the ability of $B$. monnieri to inhibit protein denaturation. The results showed that BmAE and BmME were effective in inhibiting thermally induced albumin denaturation at different concentrations. The BmAE showed the highest percentage inhibition of albumin denaturation of $44.93771 \pm 0.0071 \%$ and the lowest of $21.32969 \pm \mathbf{0 . 0 0 7 5} \%$ while BmME resulted in maximum \% inhibition of $39.14707 \pm 0.0068 \%$ and minimum \% inhibition of $15.53905 \pm 0.0065 \%$ at extract volume or amount of $1000 \mu \mathrm{l}$ and 100 $\mu \mathrm{l}$ respectively (fig. 6).

\section{Proteinase inhibitory activity}

Results exhibited significant anti-proteinase activity at different concentrations of BmAE and BmME. The BmAE demonstrated the highest percentage proteinase inhibition of $29.94818 \pm 0.0071 \%$ and the lowest of $14.47679 \pm 0.0082 \%$ while BmME resulted in maximum proteinase inhibition of $74.337 \pm 0.0073 \%$ and minimum inhibition of $25.327 \pm 0.0079 \%$ at extract volume or amount of 1000 $\mu \mathrm{l}$ and $100 \mu \mathrm{l}$ respectively (fig. 7). 


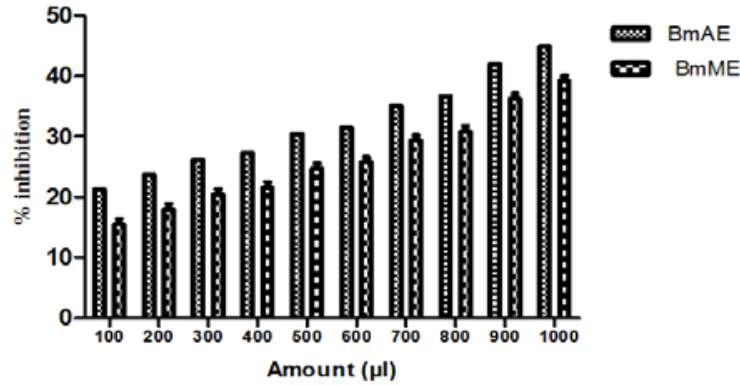

Fig. 6: Inhibition of albumin denaturation activity of methanolic and aqueous extract of $B$. monnieri was checked at various concentrations taking aspirin $(100 \mu \mathrm{g} / \mathrm{ml})$ as standard. Results represent the means \pm SEM from at least three separate experiments

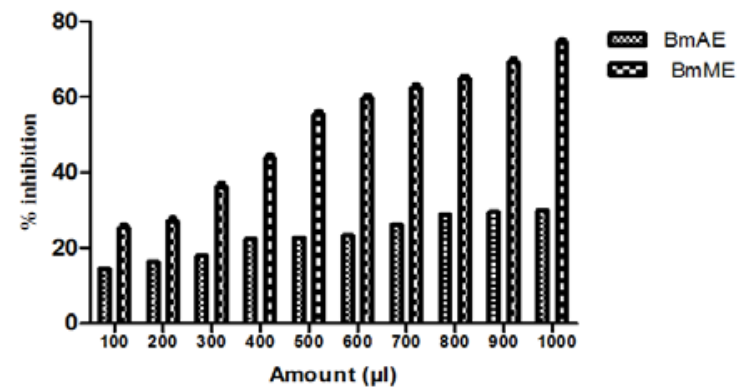

Fig. 7: \% inhibition of trypsin activity in presence of methanolic and aqueous extract of $B$. monnieri was evaluated. Results represent the mean \pm SEM from at least three separate experiments

\section{Evaluation of Antimicrobial activity}

\section{Antibacterial activity}

Antimicrobial assay of the aqueous extract was examined against various bacterial strains by accessing the percentage inhibition in presence of $B$. compared to the control where only media and cultures were added. The results suggested that BmAE and BmME exhibits bactericidal property in vitro i.e. the growth of microorganisms was inhibited in its presence. It was found that BmAE was most effective against $B$. subtilis with \%MGI of $73.912 \pm 0.0069 \%$ and was least effective against $S$. aureus with $\%$ MGI of $52.0487 \pm 0.0063 \%$. BmME showed maximum \%MGI of $79.89877 \pm 0.0081 \%$ against $B$. subtilis whereas least against $S$. aureus i.e. \%MGI of $54.789 \pm 0.0076 \%$. Whereas, synthetic antibiotic ampicillin showed almost complete inhibition against all the strain at the final concentration of $0.5 \mathrm{mg} / \mathrm{ml}$ (fig. 8).

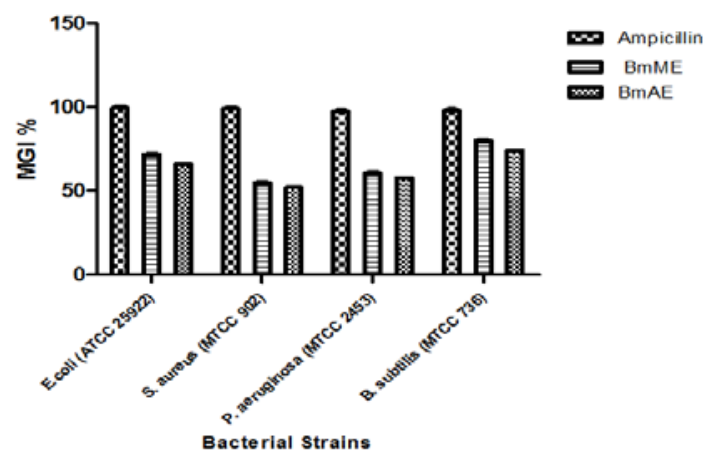

Fig. 8: Antibacterial potential of methanolic and aqueous extract of $B$. monnieri was calculated and the results were expressed in MGI (\%). Results represent the means \pm SEM from at least three separate experiments

\section{Antifungal activity}

Antifungal assay of the B. monnieri extract was performed against Candida cells (ATCC 10261 and ATCC 90028). The extract showed no zone of inhibition up to $1.5 \mathrm{mg} / \mathrm{ml}$ as well as there is no inhibition in growth of Candida cells up to $1 \mathrm{mg} / \mathrm{ml}$ in broth as well. Our results showed that BmAE and BmME showed no potent anticandidal activity up to $1 \mathrm{mg} / \mathrm{ml}$, increased concentration of extracts might lead the anticandidal effect.

\section{DISCUSSION}

B. monnieri has been traditionally used in Ayurvedic medicine to treat conditions such as fever, inflammation, pain, asthma, epilepsy, and memory decline [11]. In this study, the phytochemical screening of aqueous and methanolic extract of whole plant of $B$. monnieri revealed that among the phytocompounds investigated, presence of phenolic (total phenols, tannins and flavonoids), and non-phenolics (alkaloids, sterol, resins, terpenoids, xanthoproteins, quinones, glycosides and saponins) compounds were detected while steroids and carboxylic acid were absent. The presence of some of these secondary metabolites suggests that the plant might be of medicinal importance. The methanolic extract of $B$. monnieri gave more intense result as compared to the aqueous extract. The phytochemical constituents present in B. monnieri may be responsible for its therapeutic role and other pharmacological properties, the constituents of its which are reported here and detected during the experiments might be use for medicinal purpose. The presence of phenolic compounds (total phenols, tannins and flavonoids) provides pharmacological activities like anti-cancer, anti-oxidant, antimicrobial, and anti-inflammatory [48-53] that may suggest an association to the species here investigated.

All the plants exhibited potent antioxidant activity. Tannins and flavonoids are said to be responsible for scavenging free radical species and hence act as a major antioxidant group in plants [54]. The theory of aging skin by the action of free radicals is based on the failure mechanism of natural antioxidant in vivo and in vitro studies explain the relationship of increasing level of ROS due to loss in activity of enzymatic and non-enzymatic agents and aging. Ascorbic acid is one of the most popular natural antioxidant as in oxidizes ascorbate to dehydroascorbate and hence eliminates ROS. It also demonstrates other important physiological functions such as role as cofactor for enzymatic activity of prolyl hydroxylase, which hydroxylates prolyl leading to formation of procollagen and elastin [55].

It is common consensus that the cellular aging process can be prevented by plants' phenolic substances, which has motivated the investigation of B. monnieri metabolites and its possible action in the prevention of cellular aging. The result depicted similar pattern of antioxidant activity by BmAE, BmME and ascorbic acid (BmME being higher than BmAE) suggesting B. monnieri as a potent antioxidant source.

Inflammation is a common phenomenon and it is a reaction of living tissues towards injury. Prostaglandin- $\mathrm{E}_{2}$, an effective vasodilator in combination with histamine and bradykinin which are potent inflammatory vasodilators lead to the increased blood flow and redness in the region of acute inflammation [56]. Tannins are only remarkable for their antiseptic property but also for their astringent action. This astringent property afford them the therapeutic value in arresting haemorrhage by constructing blood vessels and in protecting wounds, inflammation and ulcer from external irritation by the participating surface protein which form impervious coating on them. Thus it is evident that the constituents are sufficient to cure infection and tannins are also responsible to cure inflammatory diseases. The results obtained support the use of B. monnieri extract locally against inflammation, ROS related diseases, fever, ulcer, infection etc.

Alkaloids being bitter substance exert notable antimicrobial action. So it is quite reasonable alkaloid containing plants show effectiveness against microbial diseases. The results show that $\mathrm{BmAE}$ and BmME both showed antibacterial activity in concentration dependent manner which was quite comparable to that of the standard drug. 


\section{CONCLUSION}

Aqueous and methanolic extracts from B. monnieri was quantified for the main phytochemicals present in extracts. The presence of various phenolics and non-phenolics phytocompounds concluded that the plant might be of medicinal importance. The varying antioxidant (free radical scavenging) activities of extracts when compared to standard antioxidant i.e. Vitamin C, suggested the possibility that the antioxidant activity of this medicinal plant may contribute to play their role against various ROS mediated disorders such as cellular aging and cancer, becoming an alternative in the fight against skin aging and cancer cells. Altogether, these results establish the therapeutic applications of $B$. monnieri and its use as herbal medicine for the prevention of inflammation and treatment of ROS and bacterial diseases. It can also be accomplished as an important mark in the field of human health and sciences. Finally, considering the results obtained, as future perspectives, we intend to evaluate some other biological activities, such as wound-healing, antimalarial, antiviral, anti-cancer activity.

\section{ACKNOWLEDGEMENT}

We are very thankful to Department of Biotechnology, Jamia Millia Islamia for providing us the infrastructure to carry out the proposed research work and we also express our sincere gratitude to Department of Science and Technology, New Delhi for their financial support.

\section{CONFLICTS OF INTERESTS}

The authors declare that they have no conflict of interest. It has not been published elsewhere. That it has not been simultaneously submitted for publication elsewhere. All authors agree to the submission to the journal.

\section{REFERENCES}

1. Patwardhan B, Hooper M. Ayurveda and future drug development. J Alternative Complementary Med 1992;10:9-11.

2. Singh SK, Patel JR, Dubey PK, Thakur S. A review on antiasthmatic activity of traditional medicinal plants. Int J Pharm Sci Res 2014;5:4109-16.

3. Chopra A, Doiphode V. Ayurvedic medicine: core concept, therapeutic principles, and current relevance. Med Clin North Am 2002;86:75-89.

4. Waxler-Morrison NE. Plural medicine in India and Sri Lanka: do ayurvedic and Western medical practices differ? Soc Sci Med 1988;27:531-44.

5. Jain SK. Ethnobotany and research on medicinal plants in India. Ciba Found Symp 1994;185:153-64.

6. Patwardhan B, Vaidya ADB, Chorghade M. Ayurveda and natural products drug discovery. Curr Sci 2004;86:6.

7. Gupta P, Khatoon S, Tandon PK, Rai V. Effect of cadmium on growth, Bacoside A, and B. side I of Bacopa monnieri (L.), a memory enhancing herb. Sci World J 2014:1-6. http://dx.doi.org/10.1155/2014/824586

8. Pengelly A. The constituents of medicinal plants. An introduction to the chemistry and therapeutics of herbal medicine. 2nd ed. Allen and Unwin, Crows Nest, Australia; 2004.

9. Petrovska BB. Historical review of medicinal plants' usage. Pharmacogn Rev 2012;6:1-5.

10. Sastri MS, Dhalla NS, Malhotra CL. Chemical investigation of Herpestis monniera Linn (Brahmi). Indian J Pharmacol 1959;21:303-4.

11. Deepak M, Amit A. The need for establishing identities of 'bacoside A and B', the putative major bioactive saponins of Indian medicinal plant Bacopa monnieri. Phytomedicine 2004;11:264-8.

12. Singh HK, Dhawan BN. Neuropsychopharmacological effects of the Ayurvedic nootropic Bacopa monnieri Linn. (Bramhi). Indian J Pharmacol 1997;29:359-65.

13. Amar J, Sharma D. Neuroprotective role of Bacopa monniera extract against aluminium-induced oxidative stress in the hippocampus of rat brain. Neurotoxicology 2006;27:451-7.

14. Chowdhuri DK, Parmar D, Kakkar P, Shukla R, Seth PK, Srimal RC. Anti-stress effects of bacosides of Bacopa monnieri: modulation of HSP to expression, Sol and cytochrome P450 activity in rat brain. Phytother Res 2002;16:639-45.
15. Chatterji N, Rastogi RP, Dhar ML. Chemical examination of Bacopa monniera Wettst: part II. The constitution of bacoside A. Indian J Chem 1965;3:24-9.

16. Mahato SB, Garain S, Chakravarty AK. Bacopasaponins E and F: two jujubogenin bisdesmosides from Bacopa monniera. Phytochemistry 2000;53:711-4.

17. Ramasamy S, Kiew LV, Chung LY. Inhibition of human cytochrome P450 enzymes by Bacopa monnieri standardized extract and constituents. Molecules 2014;19:2588-601.

18. Abascal K, Yarnell E. Bacopa for the brain: a smart addition to Western medicine. Alternative Complementary Ther 2011;17:21-5.

19. Kikuzaki H, Nakatani N. Antioxidant effects of some ginger constituents. J Food Sci 1993;58:1407-10.

20. Bafna PA, Balaraman R. Anti-ulcer and anti-oxidant activity of pepticare, a herbomineral formulation. Phytomedicine 2005;12:264-70.

21. Singh S, Eapen S, D'souza SF. Cadmium accumulation and its influence on lipid peroxidation and antioxidative system in an aquatic plant, Bacopa monnieri L. Chemosphere 2006;62:233-46.

22. Sairam K, Dorababu M, Goel RK, Bhattacharya SK. Antidepressant activity of standardized extract of Bacopa monniera in experimental models of depression in rats. Phytomedicine 2002;9:207-11.

23. Tripathi YB, Chaurasia S, Tripathi E, Upadhyay A, Dubey GP. Bacopa monniera Linn. as an antioxidant: mechanism of action. Indian J Exp Biol 1996;34:523-6.

24. Russo A, Izzo AA, Borrelli F, Renis M, Vanella A. Free radical scavenging capacity and protective effect of Bacopa monniera $\mathrm{L}$. on DNA damage. Phytother Res 2003;17:870-5.

25. Dar A, Channa S. Calcium antagonistic activity of Bacopa monniera on vascular and intestinal smooth muscles of rabbit and guinea-pig. J Ethnopharmacol 1999;66:167-74.

26. Rai D, Bhatia G, Palit G, Pal R, Singh S, Singh HK. Adaptogenic effect of Bacopa monniera (Brahmi). Pharmacol Biochem Behav 2003;75:823-30.

27. Channa S, Dar A, Anjum S, Yaqoob M. Anti-inflammatory activity of Bacopa monniera in rodents. J Ethnopharmacol 2006;104:286-9.

28. Dhanasekaran M, Tharakan B, Holcomb LA, Hitt AR, Young KA, Manyam BV. Neuroprotective mechanisms of ayurvedic antidementia botanical Bacopa monniera. Phytother Res 2007;21:965-9.

29. Uabundit N, Wattanathorn J, Mucimapura S, Ingkaninan K. Cognitive enhancement and neuroprotective effects of Bacopa monnieri in Alzheimer's disease model. J Ethnopharmacol 2010;127:26-31.

30. Mathew J, Gangadharan G, Kuruvilla KP, Paulose CS. Behavioral deficit and decreased GABA receptor functional regulation in the hippocampus of epileptic rats: effect of Bacopa monnieri. Neurochem Res 2011;36:7-16.

31. Saraf MK, Prabhakar S, Anand A. Bacopa monniera alleviates NOnitro-l-arginine-induced but not MK-801-induced amnesia: a mouse Morris water maze study. Neuroscience 2009;160:149-55.

32. Kumar RR, Kathiravan K, Muthusamy R. Bacopa monnieri a potent neuroprotector against transient global cerebral ischemia induced hippocampal damage and memory function. Int J Anal Sci 2012;3:26-32.

33. Singh A, Singh SK. Evaluation of anti-fertility potential of Brahmi in male mouse. Contraception 2009;79:71-9.

34. Dhanasekaran M, Tharakan B, Holcomb LA, Hitt AR, Young KA, Manyam BV. Neuroprotective mechanisms of ayurvedic antidementia botanical Bacopa monniera. Phytother Res 2007;21:965-9.

35. Goel R, Sairam K, Babu MD, Tavares I, Raman A. In vitro evaluation of Bacopa monniera on anti-helicobacter pylori activity and accumulation of prostaglandins. Phytomedicine 2003;10:523-7.

36. Mahitha B, Raju DP, Dillip GR, Reddy CM, Mallikarjuna K, Manoj $\mathrm{L}$, et al. Biosynthesis, characterization and antimicrobial studies of AgNPs extract from Bacopa monniera whole plant. Digest J Nanomater Biostructures 2011;6:135-42.

37. Chaudhuri PK, Srivastava R, Kumar S, Kumar S. Phytotoxic and antimicrobial constituents of Bacopa monnieri and Holmskioldia sanguine. Phytother Res 2004;18:114-7. 
38. Stough C, Lloyd J, Clarke J, Downey LA, Hutchison CW, Rodgers $\mathrm{T}$, et al. The chronic effects of an extract of Bacopa monniera (Brahmi) on cognitive function in healthy human subjects. Psychopharmacol 2001;156:481-4.

39. Stough C, Downey LA, Lloyd J, Silber B, Redman S, Hutchison C, Wesnes K, Nathan PJ. Examining the nootropic effects of a special extract of Bacopa monniera on human cognitive functioning: $90 \mathrm{~d}$ double-blind placebocontrolled randomized trial. Phytother Res 2008;22:1629-34.

40. Nathan PJ, Tanner S, Lloyd J, Harrison B, Curran L, Oliver C, et al. Effects of a combined extract of Ginkgo biloba and Bacopa monniera on cognitive function in healthy humans. Human Psychopharmacol 2004;19:91-6.

41. Santhosh W, Goveas SW, Abraham A. Evaluation of antimicrobial and antioxidant activity of stem and leaf extracts of Coscinium Fenestratum. Asian J Pharm Clin Res 2013;6:218-21.

42. Kakkar P, Das B, Viswanathan PN. A modified spectrophotometric assay of superoxide dismutase. Indian J Biochem Biophys 1984;21:130-2.

43. Jambunathan N. Determination and detection of reactive oxygen species (ROS), lipid peroxidation, and electrolyte leakage in plants. Methods Mol Biol 2010;639:292-8.

44. Moron MS, Depierre JW, Mannervik B. Levels of glutathione, glutathione reductase and glutathione S-transferase activities in rat lung and liver. Biochim Biophys Acta 1979;582:67-78.

45. Barbade KD, Datar KG. Antibacterial activity, free radical scavenging potential, phytochemical investigation and in vivo toxicity studies of medicinal plant Embelia Basaal (R. and S.) A. Dc. Asian J Pharm Clin Res 2015;8:171-7.

46. Mizushima Y, Kobayashi M. Interaction of anti-inflammatory drugs with serum proteins, especially with some biologically active proteins. J Pharm Pharmacol 1968;20:169-73.

47. Oyedepo 00, Femurewa AJ. Anti-protease and membrane stabilizing activities of extracts of Fagra zanthoxiloides, Olax subscorpioides and Tetrapleura tetraptera. Int J Pharmacogn 1995;33:65-9.

48. Lin Y, Shi R, Wang X, Shen HM. Luteolin, a flavonoid with potential for cancer prevention and therapy. Curr Cancer Drug Targets 2008;8:634-46.
49. Khacha-ananda S, Tragoolpua K, Chantawannakul P, Tragoolpua Y. Antioxidant and anti-cancer cell proliferation activity of propolis extracts from two extraction methods. Asian Pacific J Cancer Prevention 2013;14:6991-5.

50. Pourmorad F, Hosseinimehr SJ, Shahabimajd N. Antioxidant activity, phenol and flavonoid contents of some selected Iranian medicinal plants. Afr J Biotechnol 2006;5:1142-5.

51. Sengul M, Yildiz H, Gungor N, Cetin B, Eser Z, Ercisli S. Total phenolic content, antioxidant and antimicrobial activities of some medicinal plants. Pak J Pharm Sci 2009;22:102-6.

52. Hendra R, Ahmad S, Sukari A, Shukor MY, Oskoueian E. Flavonoid analyses and antimicrobial activity of various parts of Phaleria macrocarpa (Scheff.) Boerl fruit. Int J Mol Sci 2011;12:3422-31.

53. Rathee P, Chaudhary H, Rathee S, Rathee D, Kumar V, Kohli K. Mechanism of action of flavonoids as anti-inflammatory agents: a review. Inflammation Allergy: Drug Targets 2009;8:229-35.

54. Polterait 0 . Antioxidants and free-radical scavengers of Natural Origin. Curr Org Chem 1997;1:415-40.

55. Masaki H. Role of antioxidants in the skin: anti-aging effects. J Dermatol Sci 2010;58:85-90.

56. Mohamed STK, Azeem AK, Dilip C, Sankar C, Prasanth NV, Duraisami R. Anti-inflammatory activity of the leaf extacts of Gendarussa vulgaris Nees. Asian Pac J Trop Biomed 2011;1:147-9.

57. Sudha G, Priya MS, Shree RI, Vadivukkarasi S. In vitro free radical scavenging activity of raw pepino fruit (Solanum muricatum aiton). Int J Curr Pharm Res 2011;3:137-40.

58. Harborne JB. Phytochemical methods: a guide to modern techniques of plant analysis. London: Chapman and Hall; 1998.

\section{How to cite this article}

- Romana Parveen, Tooba Naz Shamsi, Himanshu Kumar, Sadaf Fatima. Phytochemical analysis and in vitro biological characterization of aqueous and methanolic extract of Васора monnieri. Int J Pharm Pharm Sci 2016;8(12):90-96. 